\title{
ПОДТВЕРЖДЕННЫЕ СЛУЧАИ РАКА ШЕЙКИ МАТКИ В БРАЗИЛИИ В ПЕРИОД С 2010 ПО 2014 ГОД
}

\section{ОРИГИНАЛЬНАЯ СТАТЬЯ}

FARIAS, Rafaela Santos ${ }^{1}$, FACCO, Lucas², FECURY, Amanda Alves ${ }^{3}$, ARAÚJO, Maria Helena Mendonça de ${ }^{4}$, OLIVEIRA, Euzébio de ${ }^{5}$, DENDASCK, Carla Viana ${ }^{6}$, SOUZA, Keulle Oliveira da ${ }^{7}$, DIAS, Claudio Alberto Gellis de Mattos ${ }^{8}$

FARIAS, Rafaela Santos. Et al. Подтвержденные случаи рака шейки матки в Бразилии в период с 2010 по 2014 год. Revista Científica Multidisciplinar Núcleo do Conhecimento. 05-й год, Эд. 11, Vol. 25, стр. 93-104. Ноябрь 2020 года. ISSN: 2448-0959, Ссылка доступа:

https://www.nucleodoconhecimento.com.br/здравоохранение/случаи-рака-шейки,

DOI: 10.32749/nucleodoconhecimento.com.br/ru/67822

\section{PEЗЮME}

Мазок Папаниколау (PCCU) является гинекологическое обследование, выполнено у женщин для того, чтобы обнаружить повреждение шейки матки. Изменения могут наблюдаться как расстройство тканей, что составляет его. Цель этой работы состоит в том, чтобы показать подтвержденные случаи рака

\footnotetext{
${ }^{1}$ Горнодобывающая техника, в результате Федерального института Amapá (IFAP).

${ }^{2}$ Студент медицинского курса Федерального университета Amapá (UNIFAP).

${ }^{3}$ Биомедицинская, кандидат биологических наук в области тропических болезней, профессор и исследователь медицинского курса Федерального университета Amapá (UNIFAP).

${ }^{4}$ Врач, профессор и исследователь медицинского курса Федерального университета Amapá (UNIFAP).

${ }^{5}$ Биолог, кандидат медицинских наук по актуальным заболеваниям, профессор и исследователь курса физкультуры Федерального университета Pará (UFPA).

${ }^{6}$ Богослов, кандидат психологических наук, исследователь Центра исследований и перспективных исследований - СЕРА.

${ }^{7}$ Социолог, студент магистратуры по антропогенным исследованиям в Амазонии, член исследовательской группы "Лаборатория образования, окружающей среды и здоровья" (LEMAS/UFPA). ${ }^{8}$ Биолог, кандидат теоретических и летных исследований, профессор и исследователь Высшей программы профессионального и технологического образования (PROFEPT), Федеральный институт Amapá (IFAP).
}

RC: 67822

Disponível em: 
шейки матки в Бразилии в период с 2010 по 2014 год. Исследование проводилось на основе данных DATASUS (http://datasus.saude.gov.br). При хорошей работе по профилактике заболевания, которое считается серьезным, результат является удовлетворительным и эффрективным. Благодаря результатам, полученным путем анализа данных в период с 2010 по 2014 год, соответственно, делается вывод, что с годами поиск теста постепенно увеличивался, но некоторые аспекты сохранялись, такие как стыд выполнения теста PCC, страх, боль, среди других. Однако результаты показали высокий уровень испытаний в юго-восточном регионе и более низкий показатель на севере, при этом женщины в северном регионе были слабо осведомлены о них. Поэтому распространение, осведомленность и эфффективность цитопатологического обследования очень важны для профилактики рака шейки матки, который сегодня является основной причиной смертности среди бразильских женщин

Ключевые слова: Эпидемиология, рак шейки матки, PCCU, Цитопатология.

\section{ВВЕДЕНИЕ}

Профрилактические тесты проводятся для выявления возможных заболеваний и лечения их в начале (BRASIL, 2013). Мазок Папаниколау (PCCU) является гинекологическое обследование, выполнено у женщин для того, чтобы обнаружить повреждение шейки матки, которые могут стать вредными для здоровья (TEIXEIRA и др., 2015). Этот тест используется для обнаружения ранних изменений в шейке матки. Он помогает в ранней диагностике рака у женщин, и может рассматриваться в его первоначальном состоянии, тем самым избегая увеличения смертности среди женщин (ARA'JO и др., 2016). Это обследование должно проводиться женщинами, которые имеют сексуально активную жизнь или которые старше 18 лет. Он опирается на сбор и анализ образцов шейки матки для выявления рака (BARBER et al., 2009).

$\mathrm{RC}: 67822$

Disponível em: 
Изменения могут наблюдаться как расстройство тканей, которое составляет шейку матки. Это расстройство можно разделить на степени. Оценка 1 (I) происходит, когда небольшое расстройство клеток происходит, компрометируя мелкие части ткани. Когда это клеточное расстройство достигает до трех четвертей ткани, он считается в классе 2 (II). В iii степени (III) отмечается, что расположение клеток полностью неупорядоченные, выявление так называемого рака шейки матки (MENETRIER и др., 2016).

Количество экзаменов PCCU, выполненных в Бразилии в 2010 году, составило около 10 миллионов экзаменов в год. Это количество пап мазка сканирования варьировались между бразильскими регионами. В северном регионе было проведено 603738 (шестьсот три тысячи семисот тридцать восемь) обследований. В северо-восточном регионе было проведено 2616344 (два миллиона шестьсот шестнадцать тысяч триста сорок четыре) обследования. На Среднем Западе было проведено 745875 (семьсот сорок пять тысяч восемьсот семьдесят пять) экзаменов. На юго-востоке было обследовано 4703400 человек (четыре миллиона семьсот три тысячи четыреста человек). В южном регионе 1606119 (один миллион шестьсот шестьсот шестьсот девятнадцать) экзаменов (БОРТОЛОН и др., 2012).

Количество экзаменов PCCU, выполненных в 2010 году в северном регионе Бразилии, варьируется в зависимости от каждого штата, который его составляет. В Амапа было проведено 19657 (девятнадцать тысяч шестьсот пятьдесят) экзаменов. В Акко было проведено 53754 (пятьдесят три тысячи семисот пятидесяти четырех) обследований. В амазонах проведено 134.268 (Сто тридцать четыре тысячи двести шестьдесят восемь) обследований. В штате Паре 191298 (Сто девяносто одна тысяча двести девяносто восемь) экзаменов. В Рондонии проведено 92085 (девяносто две тысячи восемьдесят два) обследования. В штате Рорайма было проведено 28614 (двадцать восемь тысяч шестьсот четырнадцать) обследований. В Токантине было проведено 84

RC: 67822

Disponível em: 
062 (восемьдесят четыре тысячи шестьдесят два) теста (BORTOLON et al., 2012).

\section{ЦЕЛЬ}

Показать подтвержденные случаи рака шейки матки в Бразилии в период с 2010 по 2014 год.

\section{МЕТОД}

Исследование проводилось с данными, взятыми из DATASUS (http://datasus.saude.gov.br) после следующих шагов: во-первых, "доступ к информации" Тab был выбран, а затем вариант "информация о здоровье (TABNET)" вскоре после суб-вариант "Эпидемиологические и заболеваемости" после доступа к варианту группы "Рак шейки матки и молочной железы (SISCOLO/ SISMAMA). Далее была выбрана икона "Рак шейки матки и молочной железы - с 2000 года". Была открыта вкладка "Сисколо 4.00 и выше" и выбрана опция "Цервико-вагинальное цитопатологическое обследование и микрофрлора-процедура 12.011.01-0". Затем нажал на "Бразилия / регионы". Для сбора данных был выбран вариант "Год компетентности" в области строки. В поле содержания была выбрана опция "Количество экзаменов". В поле столбца варианты были "Не активны"; "год компетентности"; Год компетентности"; "Reg.resid'ncia"; "Школьное образование"; "Цвет/Гонка"; "В нормальных пределах"; "Интерв собирает"; "Интерв результат"; "Цитопатол.Предыдущий"; и "Время.Предотвратить". По всем вариантам данные были собраны с 2010 по 2014 год. Опция «Месяц/год компетентности» также была выбрана в поле столбца в поле столбца, а в поле содержания - в варианте «Количество экзаменов» на те же годы. Данные были собраны в приложении Excel, компоненте пакета Microsoft Corporation Office. Библиографические исследования проводились в научных статьях, используя для поиска компьютеры компьютерной лаборатории Федерального института образования,

RC: 67822

Disponível em: 
науки и техники Амапе, Кемпус Макапе, расположенный по адресу: Rodovia BR 210 KM 3, s/n - Bairro Brasil Novo, CEP: 68.909-398, Макапе, Амапе, Бразилия.

\section{РЕЗУЛЬТАТЫ}

На рисунке 1 показан процент пап мазка сканирования (PCCU) осуществляется в Бразилии в период с 2010 по 2014 год. В период с 2010 по 2013 год количество испытаний оставалось практически стабильным. Данные за 2014 год свидетельствуют о резком снижении успеваемости экзаменов в стране.

На рисунке 1 показан процент пап мазка сканирования (PCCU) осуществляется в Бразилии в период с 2010 по 2014 год.

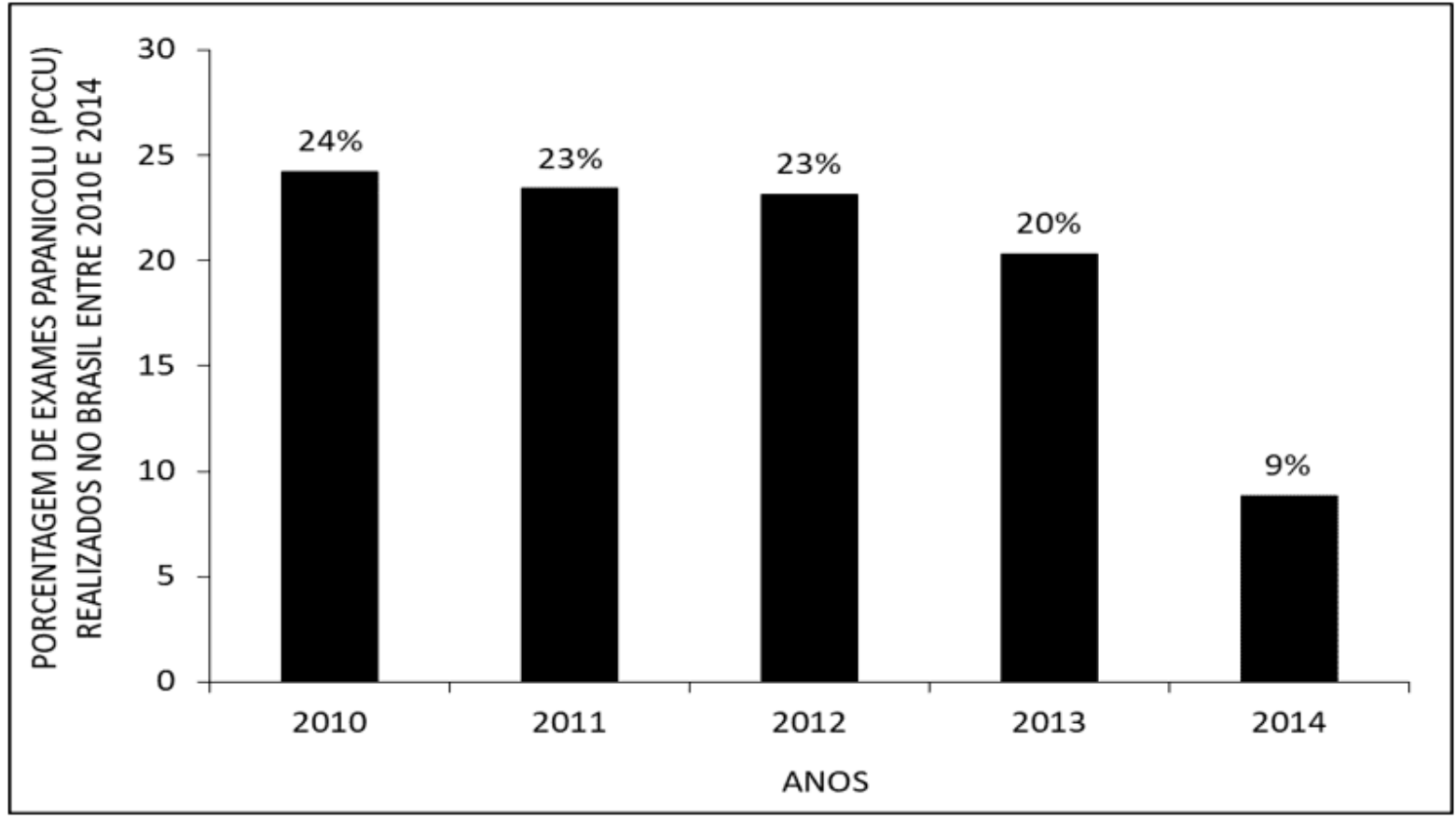

На рисунке 2 показан процент пап мазка сканирования, выполненного в Бразилии в период с 2010 по 2014 год, в регионах страны. Показаны более высокие темпы испытаний, проведенных в юго-восточном регионе, и меньшее

RC: 67822

Disponível em: 
число испытаний в северо-восточном, южном, среднем и северном регионах, соответственно.

На рисунке 2 показан процент пап мазка сканирования (PCCU), выполненных в Бразилии в период с 2010 по 2014 год, в регионах страны.

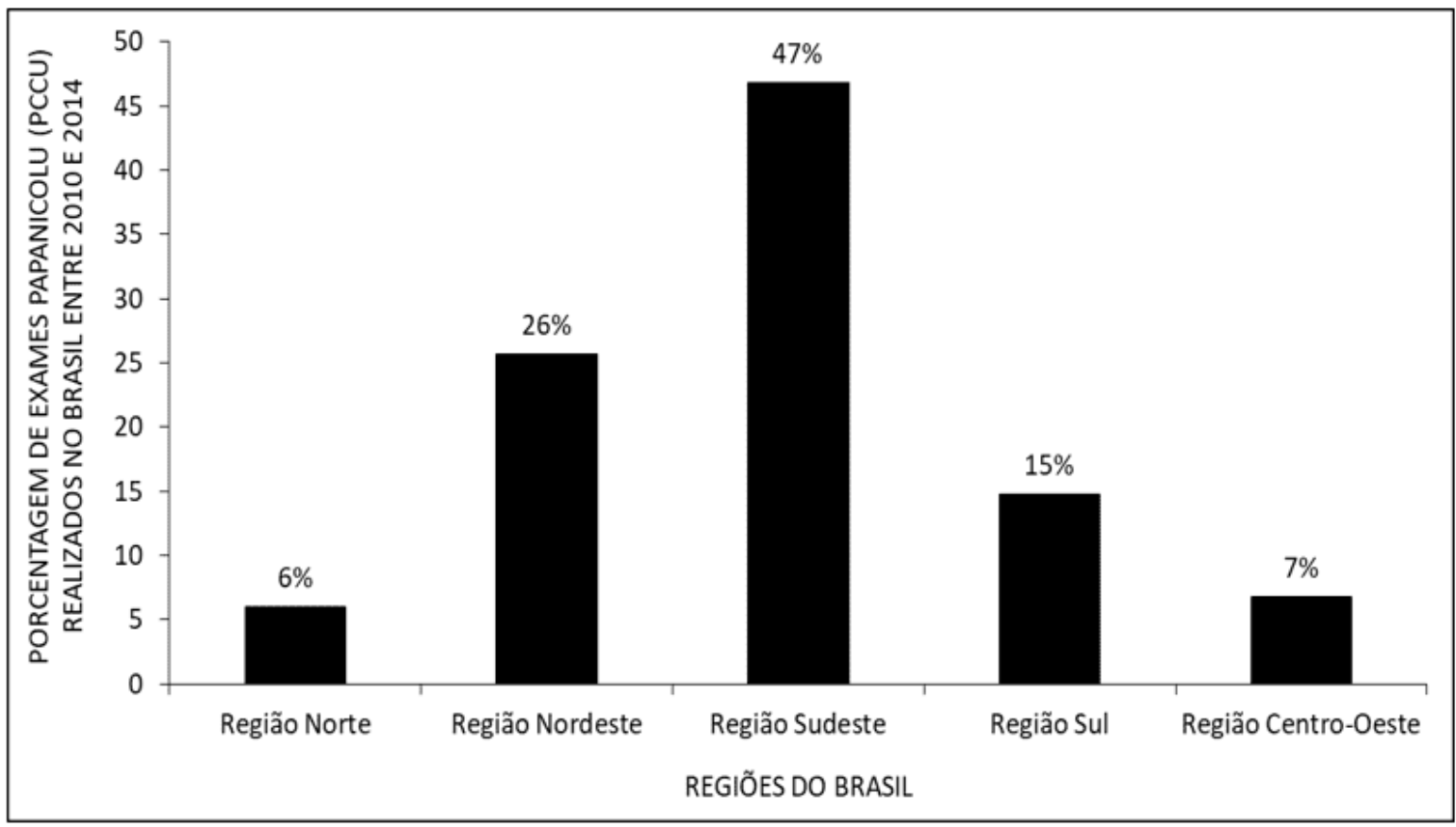

На рисунке 3 показан процент пап мазка сканирования (PCCU) осуществляется в Бразилии в период с 2010 по 2014 год, в зависимости от возрастной группы. Данные показывают, что наибольшее количество тестов проводится среди женщин в возрасте от 30 до 39 лет. Самая маленькая - в возрастной группе женщин до 19 лет.

$\mathrm{RC}: 67822$

Disponível em:

https://www.nucleodoconhecimento.com.br/здравоохранение/случаи-рака-шейки 
На рисунке 3 показан процент пап мазка сканирования (PCCU) осуществляется в Бразилии в период с 2010 по 2014 год. в зависимости от возрастной группы.

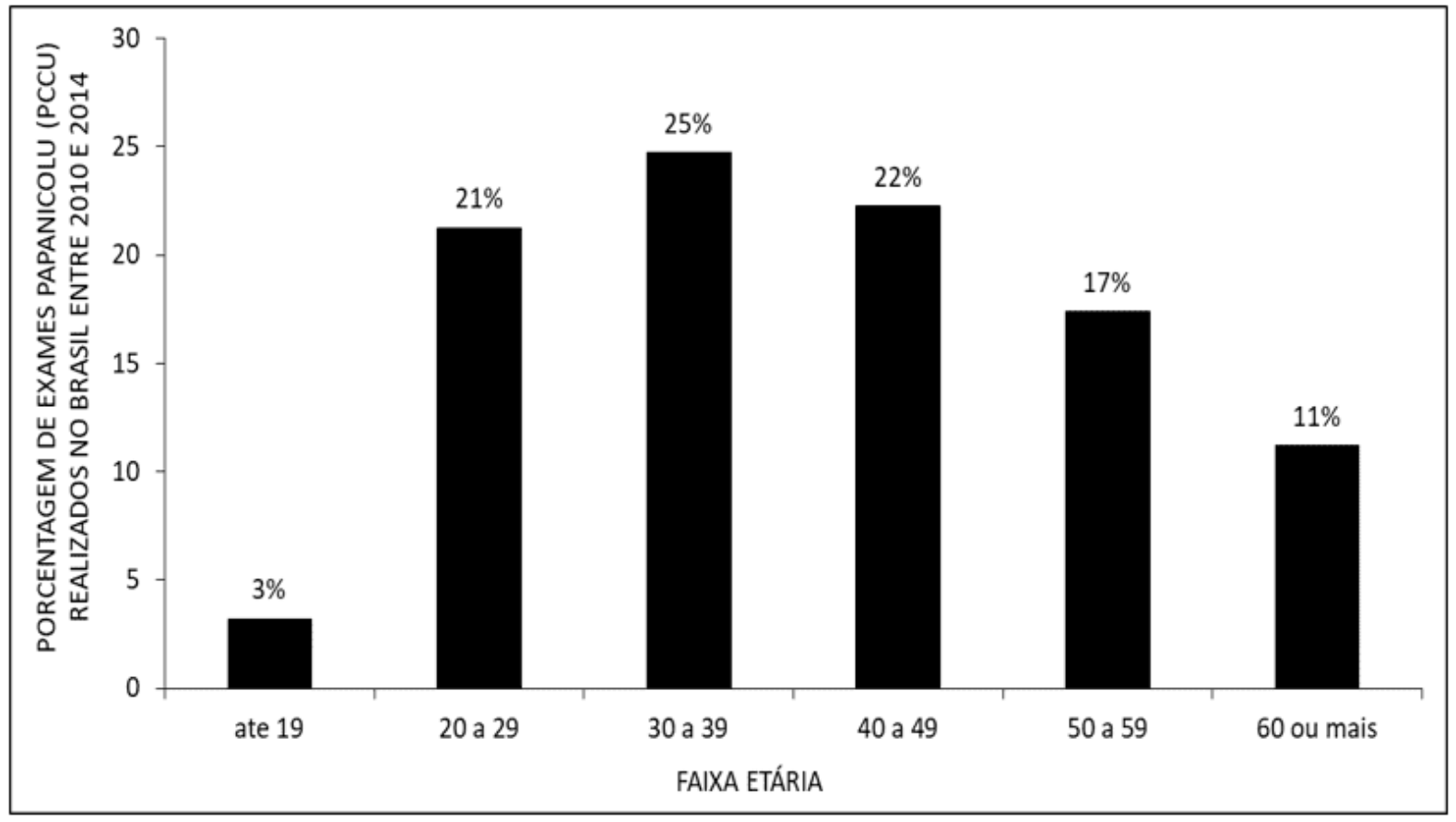

На рисунке 4 показан процент пап мазка сканирования (PCCU) осуществляется в Бразилии в период с 2010 по 2014 год, путем школьного обучения. Показывает, что большинство женщин, которые сдают экзамен имеют неполную начальную школу. В то время как самая маленькая сумма завершила высшее образование.

RC: 67822

Disponível em: 
На рисунке 4 показан процент папо-мазковых тестов (PCCU), проведенных в Бразилии в период с 2010 по 2014 год, путем школьного обучения.

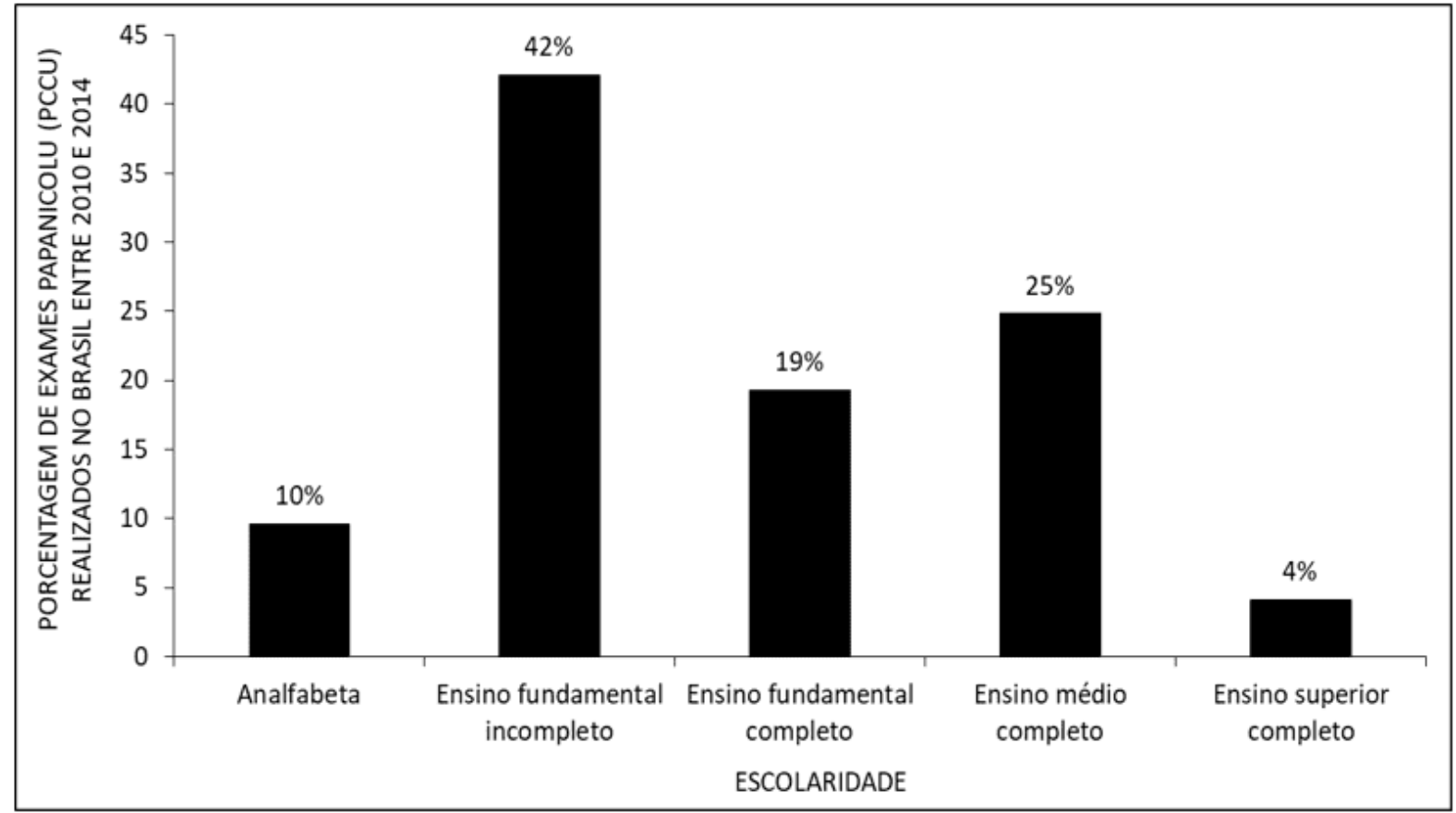

На рисунке 5 показан процент пап мазка сканирования (PCCU) осуществляется в Бразилии в период с 2010 по 2014 год, по этническому признаку. По сравнению с чернокожими, желтыми и коренными женщинами женщины белого и коричневого этнического происхождения проводят большое количество тестов.

RC: 67822

Disponível em: 
На рисунке 5 показан процент пап мазка сканирования (PCCU) осуществляется в Бразилии в период с 2010 по 2014 год, по этническому признаку.

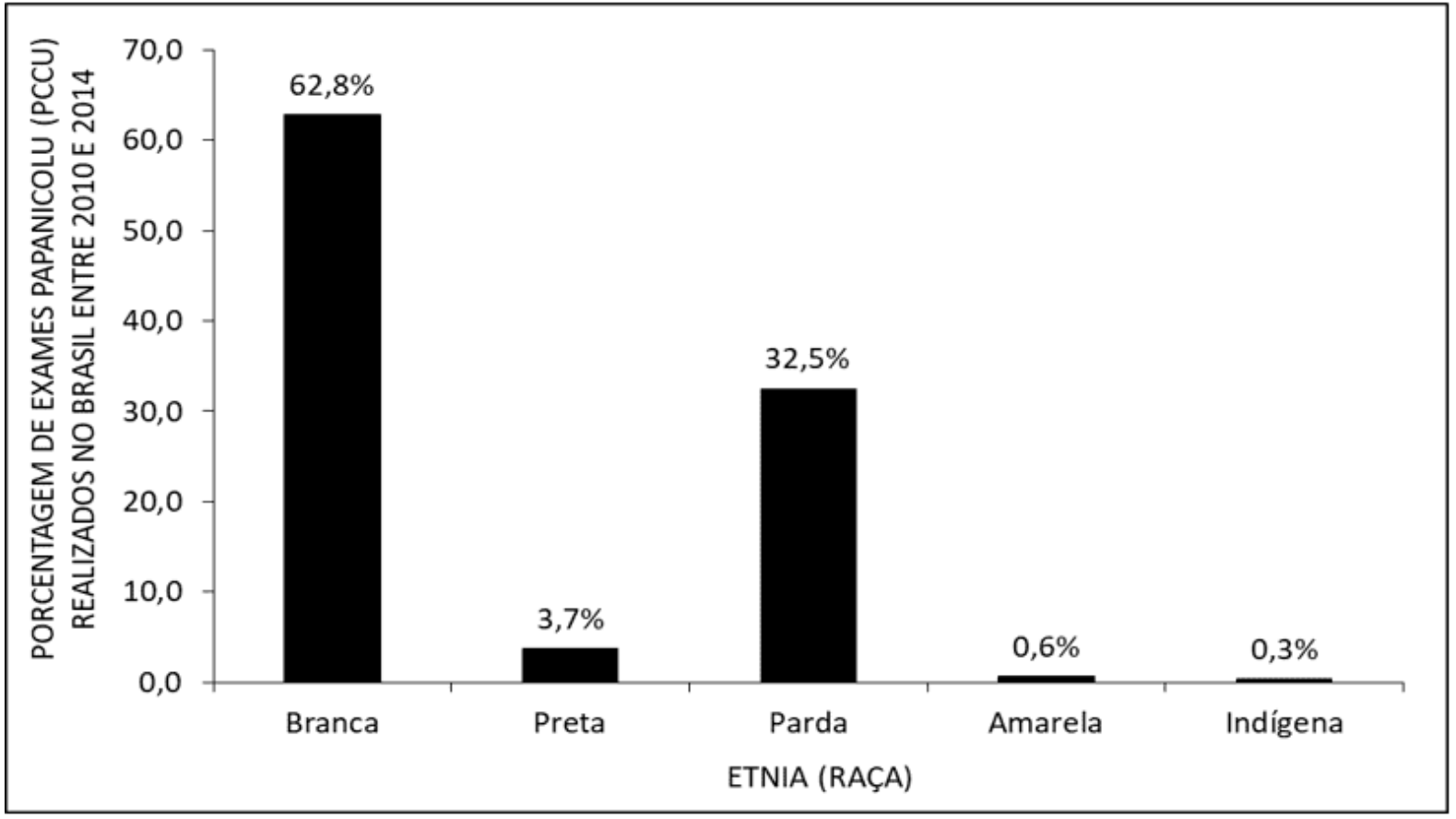

На рисунке 6 показан процент пап мазка сканирования, выполненного в Бразилии, в пределах нормального диапазона, в период с 2010 по 2014 год. Среди проведенных тестов данные показывают, что большинство из них не находится в пределах нормального диапазона.

RC: 67822

Disponível em: 
На рисунке 6 показан процент папо-мазковых тестов, проведенных в Бразилии в пределах обычного диапазона в период с 2010 по 2014 год.

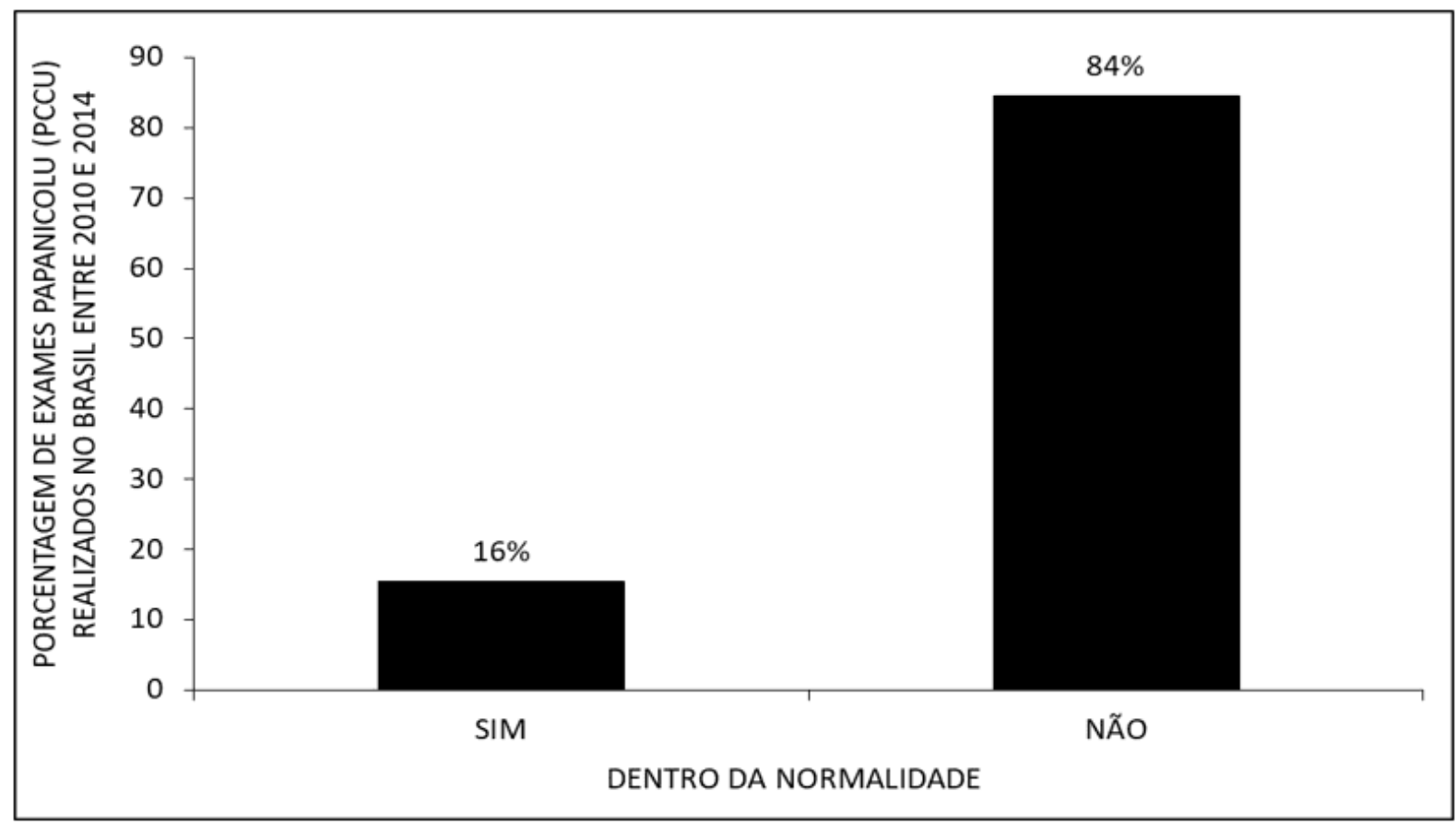

На рисунке 7 показан процент пап мазка сканирования (PCCU) осуществляется в Бразилии в период с 2010 по 2014 год, в интервал сбора. Тесты в основном собирались с интервалом до 10 дней, в то время как самая маленькая сумма имеет интервал сбора более 30 дней.

RC: 67822

Disponível em:

https://www.nucleodoconhecimento.com.br/здравоохранение/случаи-рака-шейки 
На рисунке 7 показан процент папских мазковых тестов (PCCU), проведенных в Бразилии в период с 2010 по 2014 год, с интервалом сбора.

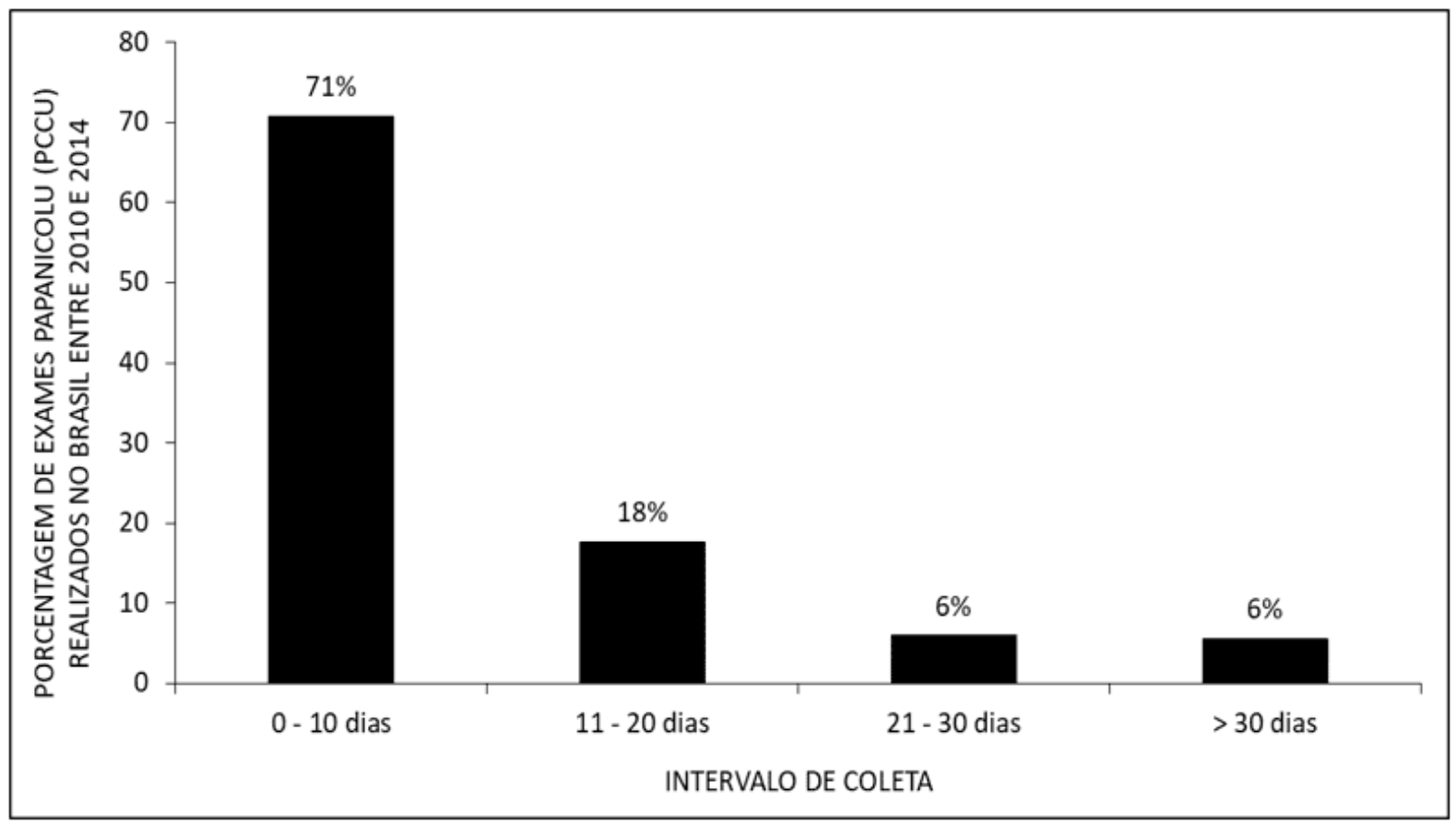

На рисунке 8 показан процент пап мазка сканирования (PCCU) осуществляется в Бразилии в период с 2010 по 2014 год, в результате интервал. Показывая, что большинство результатов были выпущены в течение 10 дней. Хотя самое маленькое количество в более чем 30 дней.

RC: 67822

Disponível em: 
На рисунке 8 показан процент папо-мазковых тестов (PCCU), проведенных в Бразилии в период с 2010 по 2014 год, с интервалом в результате.

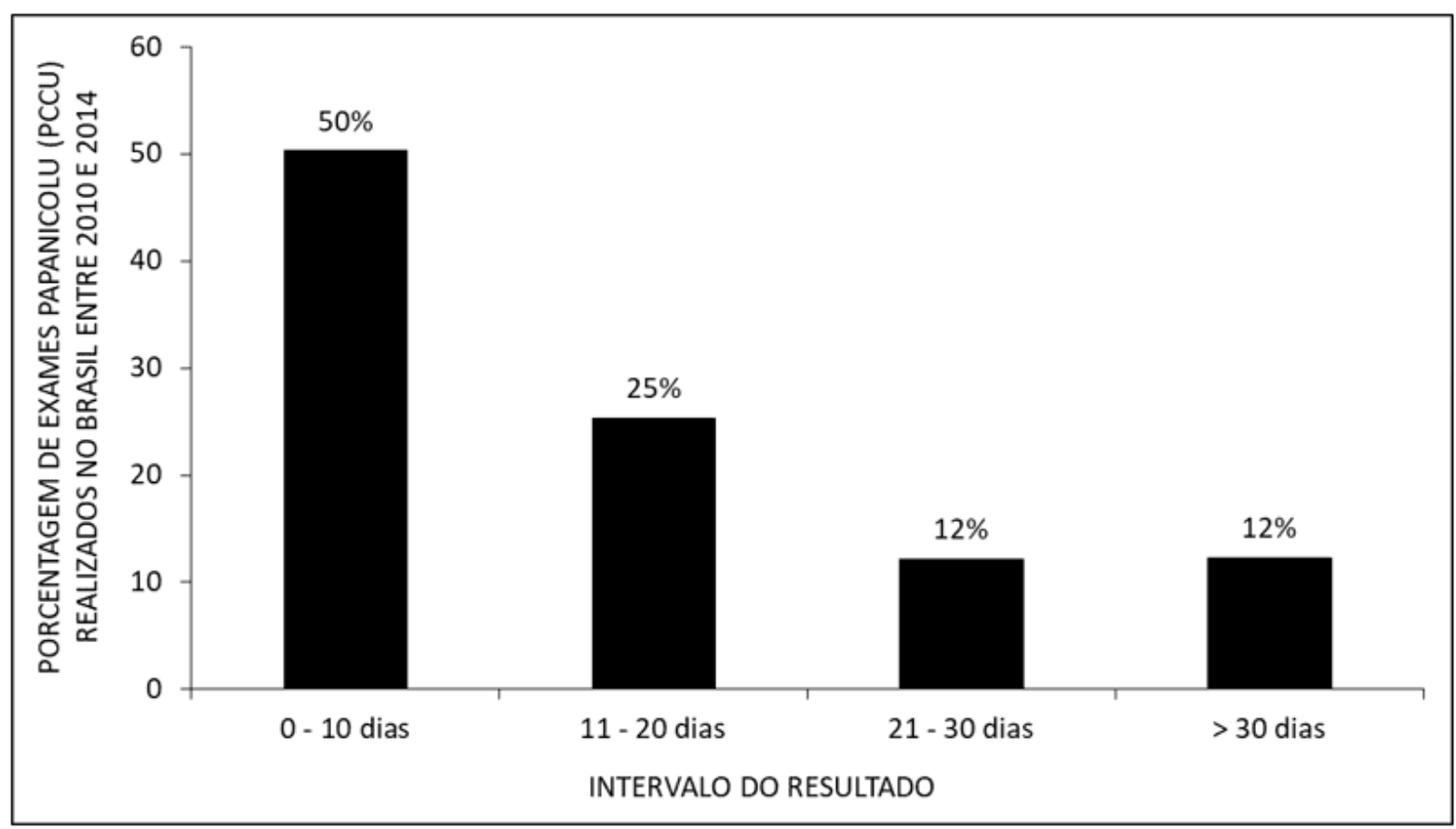

На рисунке 9 показан процент пап мазка сканирования (PCCU), выполненных в Бразилии в период с 2010 по 2014 год, согласно предыдущему цитологическому исследованию. Большинство обследованных женщин ранее прошли тесты.

RC: 67822

Disponível em: 
На рисунке 9 показан процент пап мазка сканирования (PCCU), выполненных в Бразилии в период с 2010 по 2014 год, согласно предыдущему цитологическому исследованию.

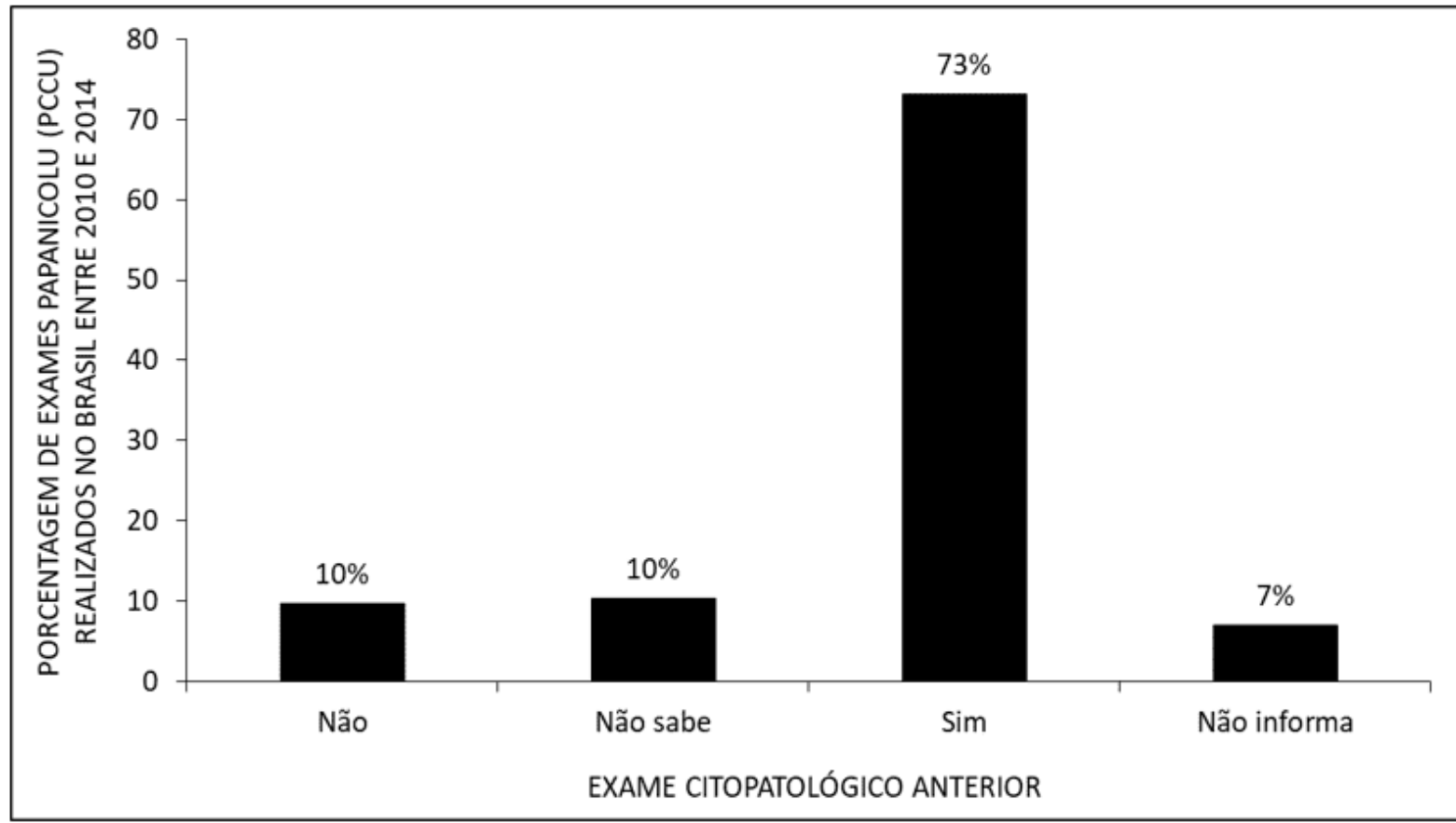

Рисунок 10 показывает процент пап мазка сканирования (PCCU) осуществляется в Бразилии в период с 2010 по 2014 год, в соответствии с моментом последнего профилактического. Данные показывают, что большинство женщин сдают экзамены из года в год.

RC: 67822

Disponível em: 
На рисунке 10 показан процент папо-мазковых тестов (PCCU), проведенных в Бразилии в период с 2010 по 2014 год, в соответствии с моментом последней просрилактики.

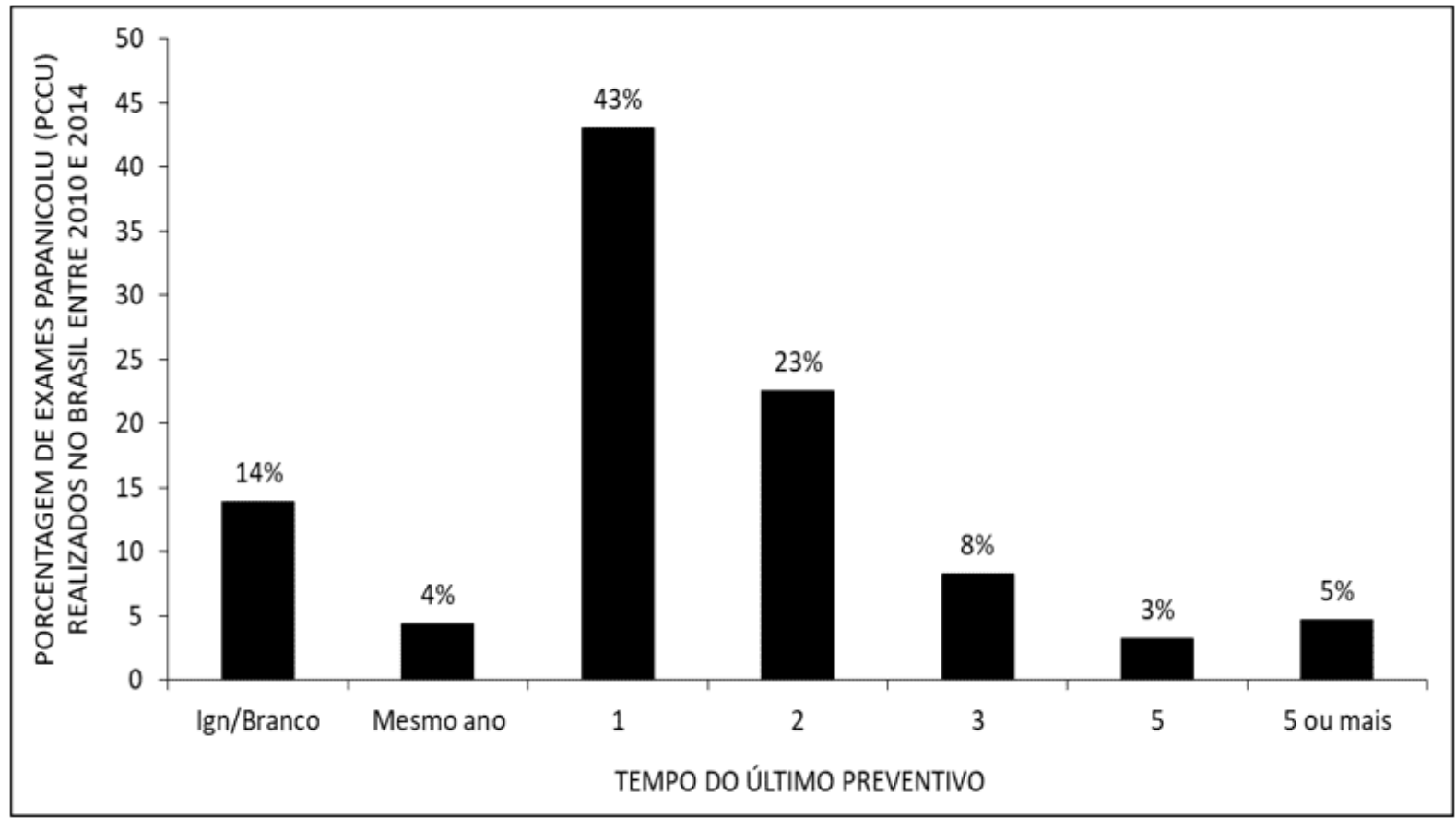

\section{ОБСУЖДЕНИЯ}

Данные свидетельствуют о заметном снижении эффрективности испытаний в стране (рисунок 1). Некоторые фракторы, как представляется, влияют на это снижение, такие, как отсутствие знаний о важности экзамена и страх перед экзаменом; стыд воздействия гениталий; трудности с доступом к УБС; отсутствие подготовки специалистов в отношении уважения, руководства и информации, предоставляемой пациентам об обследовании (SANTOS и VARELA, 2015).

Данные свидетельствуют о более высоком уровне обследований в юговосточном регионе и меньшем числе тестов в северо-восточном, южном, среднем и северном регионах, соответственно (рисунок 2). Это основано на

RC: 67822

Disponível em: 
знаниях, информации и осведомленности женщин в области профилактики рака шейки матки. В других регионах было низкая положительность тестов. В результате, Амапа, которая находится в Северном регионе, обнаружила меньше испытаний, достигнув процент ниже 1,0\% положительности. А также в северо-восточных, южных и средних регионах. Было замечено, что эти регионы не имеют участия и осведомленности женщин, потому что низкие научные знания об исполнении экзамена является фактором, который, в любом случае, может помешать поиску экзамена рсси. Некоторые причины оправдывают этот фракт, такие как стыд, чувство страха, смущение во время осмотра, нехватка времени, отсутствие интереса и отсутствие информации о цитопатологической экспертизе (БОРТОЛОН и др., 2012).

Данные свидетельствуют о том, что наибольшее число тестов проводится среди женщин в возрасте от 30 до 39 лет и самое низкое число среди женщин в возрасте до 19 лет (рисунок 3). Начало сбора экзаменов должно быть в 25 лет независимо от того, имеет ли пациент активную сексуальную жизнь или нет. Большое количество мазка Папаниколау выполняется в возрастных группах от 30 до 39 лет, согласно таблице. Обследование должно продолжаться до 64 лет и должно быть прервано после выполнения двух тестов, результаты которых являются отрицательными, два теста должны быть выполнены с интервалом от одного до трех лет. Все женщины, которые имеют активную сексуальную жизнь или старше 18 лет в состоянии выполнить профилактическое обследование рсси, но этот тест еще не полностью приобретены бразильских женщин, известно, что Бразилия имеет высокий уровень смертности от рака шейки матки. Это связано с тем, что большинство женщин обращаются за медицинской помощью в более продвинутой степени, что чаще всего происходит у женщин в возрасте от 30 до 39 лет. Согласно таблице 3, было проанализировано, что наименьшее количество проведенных тестов среди женщин в возрасте 19 лет, именно из-за отсутствия информации об экзамене рсси и страха его проведения (BRASIL, 2014).

$\mathrm{RC}: 67822$

Disponível em: 
Большинство женщин, са принимающих экзамен, имеют неполное начальное образование и высшее образование меньшинств (рисунок 4). В этой таблице было отмечено, что чем больше исследований и школьного образования у женщин, тем меньше они заинтересованы в проведении профилактического осмотра пкку. Причина такого результата связана с убеждениями и отношением к здоровью. 29,6\% сообщили, что не помнят, почему они не присутствовали на тесте. Некоторые причины из-за страха, стыда, дискомфорта и боли. Мы получили неожиданные результаты в таблице 4, потому что мы заметили высокий уровень количества экзаменов pccu, выполняемых женщинами, которые имеют неполную начальную школу, потому что, как правило, женщины, которые не имеют неполного школьного образования, как правило, строят семьи раньше, и в результате, у них больше детей, чем женщин, которые имеют более высокий уровень образования. Следовательно, эти женщины чаще ходят к врачу, получая высокий уровень мазка Папаниколау (SILVA et al.,2015).

По сравнению с чернокожими, желтыми и коренными женщинами (рисунок 5) женщины белого и коричневого этнического происхождения проводят большое количество тестов. Было замечено, что значительная часть мазка, не связанного с папой, связана с этнической принадлежностью, и большая часть этого сопротивления связана с такими фракторами, как неравенство расы/этнической принадлежности, а также с ограниченным доступом, который имеет тот или иной раса. Как показано в таблице (5). Однако низкий охват и отсутствие доступа среди других групп объясняется доступом и диффреренцированным лечением, которое они имеют по мере прибытия на место экзамена (PINHO E JUNIOR, 2003).

Данные показывают, что большинство выполненных тестов не находятся в пределах обычного диапазона (рисунок 6). Значительная часть женского населения является из обычных при выполнении мазка Папаниколау. Это

RC: 67822

Disponível em: 
потому, что женщины стремятся сдать экзамен в несколько более продвинутом состоянии. Это также объясняется тем фрактом, что большинство женщин имеют более одного сексуального партнера, с тенденцией к заражению ВПч (вирус папилломы человека), венерических заболеваний. Там, где может быть клеточная дезорганизация в ткани, которая составляет шейку матки (NORONHA и др., 2005; OLIVEIRA et al., 2016)).

Тесты в основном собирались с интервалом до 10 дней, а самая маленькая сумма имела интервал сбора более 30 дней (рисунок 7). Интервал сбора чаще всего короче и имеет интервал продолжительностью 10 рабочих дней. Профрессионал читает лезвие и отращывает результат в этот период, обследование пкку собирается во время гинекологической консультации, а во время консультации вводится вагинальный спектрул без каких-либо смазочных действий, которые могут вызвать небольшой дискомфорт. Перед сбором пациент не должен заниматься сексом накануне. Это должно быть выполнено вне менструации, чтобы получить более эффрективный результат (BRITO и NERY, 2007).

Большинство результатов были опубликованы в течение 10 дней и наименьшее количество более чем за 30 дней (рисунок 8). Что касается мазка Папаниколау, 46,55\% женщин прошли тест. Тем не менее, 57,8\% работают в частных сетях, и результаты экзамена гораздо быстрее, так как результаты женщин, которые выполняют рсси экзамен по сети SUS, который имеет больше времени доставки, чем ожидалось (MURATA и др., 2012).

Большинство опрошенных женщин ранее прошли тесты (рисунок 9). Среди женщин, которые знают об экзамене PCCU, большинство из них выполняют экзамен часто, или выступали раньше. Полагая, что с выполнением рсси обследования в определенные периоды будет избегать, таким образом, будущие заболевания, такие как рак шейки матки. Потому что это эффективный

$\mathrm{RC}: 67822$

Disponível em: 
тест, который, если диагноз в начале, он может иметь 100\% шанс на излечение (BARBEIRO и др., 2009).

Данные показывают, что большинство женщин сдают экзамены из года в год (рисунок 10). Большинство женщин идут к врачу, чтобы выполнить обследование рака шейки матки с целью профилактики заболеваний, и лечить их в первую очередь, чтобы избежать проблем в будущем. Рекомендуется проводить экзамен рсси ежегодно, из года в год, для анализа и оценки, если было или произошло какое-либо изменение, как это было в результате предыдущего экзамена. женщины, заботясь о своем здоровье, сдают экзамен с периодами времени от 1 до двух лет, как показано на рисунке (10) (PINHO and JUNIOR, 2003; МЕЛО и др., 2019).

\section{ЗАКЛЮЧЕНИЕ}

Это исследование показало, что, когда есть хорошие показатели для предотвращения болезни считается тяжелой, результат является удовлетворительным и эффрективным. Важно, чтобы у них были раскрытия и информация о проффилактическом обследовании, но известно, что сама профилактика проводится только с выполнением мазка Папаниколау для раннего выявления уровня степени, что рак. Это при лечении на первый имеет высокие шансы на излечение.

Благодаря результатам, полученным путем анализа данных в период с 2010 по 2014 год, соответственно, делается вывод, что с годами поиск теста постепенно увеличивался, но некоторые аспекты сохранялись, такие как стыд выполнения теста PCС, страх, боль, среди других. Однако результаты показали высокий уровень обследований в юго-восточном регионе и более низкий показатель в северном регионе. Данные свидетельствуют о низком уровне раскрытия инфрормации и низкой осведомленности женщин в северном регионе. Поэтому распространение, осведомленность и эфффективность цитопатологического

$\mathrm{RC}: 67822$

Disponível em: 
обследования очень важны для профрилактики рака шейки матки, который сегодня является основной причиной смертности среди бразильских женщин

\section{ссылкИ}

ARAÚJO, R.M.; CUNHA, H.C.O.; FERREIRA, V.G.C.; TRINDADE, M.P.; SOUZA, H.S.L. a importância da realização do exame papanicolau como instrumento de prevenção do câncer de colo do útero: uma revisão integrativa de literatura, Anais do V Congresso de Educação em Saúde da Amazônia. COESA. Universidade Federal do Pará. 2359-084. 2016.

BARBEIRO, F.M.S.; CORTEZ, E.A.; OLIVEIRA, P.A.M.C.; SILVA, A.L.O.; conhecimentos e práticas das mulheres acerca do exame papanicolau e prevenção do câncer cérvico-uterino. Cuidado é fundamental. 1(2):414-422. 2009.

BORTOLON, P.C.; SILVA, M.A.F.; CORRÊA, F.M.; DIAS, M.B.K.; KNUPP, V.M.A.; ASSIS, A.; CLARO, I.B. Avaliação da Qualidade dos Laboratórios de Citopatologia do Colo do Útero no Brasil. Revista Brasileira de Cancerologia. 58(3),435444,2012 .

BRASIL. Ministério da Saúde. Secretaria de Atenção à Saúde. Departamento de Atenção Básica. Controle dos cânceres do colo do útero e da mama / Ministério da Saúde, Secretaria de Atenção à Saúde, Departamento de Atenção Básica. - 2. ed. - Brasília: Editora do Ministério da Saúde, 2014. 124 p.

BRASIL. Ministério da Saúde. Secretaria de Atenção à Saúde. Departamento de Atenção Básica. Controle dos cânceres do colo do útero e da mama. Ministério da Saúde. 2. ed. - Brasília: Editora do Ministério da Saúde. 124 p. 2013.

MELO, Carolina Simas. Et al. Caracterização epidemiológica dos óbitos no Brasil por macrorregião de 2016 a 2018. Revista Científica Multidisciplinar

$\mathrm{RC}: 67822$

Disponível em: 
Núcleo do Conhecimento. Ano 04, Ed. 12, Vol. 01, pp. 05-17, 2019. Link de acesso: https://www.nucleodoconhecimento.com.br/saude/obitos-no-brasil

MENETRIER, J.V.; BOING, A.; MEDEIROS, K.A. Alterações citopatológicas do colo uterino em mulheres atendidas na 8a Regional de Saúde do Paraná no ano de 2014. Espaço para a Saúde - Revista de Saúde Pública do Paraná. V. 17, n. 2, p. 169177, 2016.

MURATA, I.M.H.; GRABRIELLONI, M.C.; SCHIRMER J. Cobertura do Papanicolau em mulheres de 25 a 59 anos de Maringá - PR, Brasil. Rev Bras Cancerol.58(3):409-15, 2012.

NORONHA, V.L.; NORONHA, R.; CARMONA, B.; MACEDO, L.A.; CRUZ, E.M.; NAUM, C.; MELLO, W.; VILLA, L. Papilomavírus humano (hpv) em mulheres com citologia oncótica dentro dos limites da normalidade. ARTICLE. 17(1): 49-55, 2005.

OLIVEIRA, R.C.E.. et. al. Perfil epidemiológico do HPV da população feminina sexualmente ativa, na faixa etária de 10 a 80 anos. Revista Científica Multidisciplinar Núcleo do Conhecimento. Ano 01, Ed. 07, Vol. 04, pp. 21-34, 2016. Link de acesso: https://www.nucleodoconhecimento.com.br/saude/hpv

PINHO, A.A; JUNIOR, I.F. Prevenção do câncer de colo do útero: um modelo teórico para analisar o acesso e a utilização do teste de Papanicolaou. Rev. Bras. Saude Mater. Infant. n.1 Recife jan./mar. 2003.

RICO, A.M.; SILVA, G.A.; LOWY, I.; TEIXEIRA, L. (Org.) et al. Câncer de mama, câncer de colo de útero: conhecimentos, políticas e práticas. Outras Letras. 256 p. 2015.

SANTOS, A.C.S.; VARELA, C.D.S. Prevenção do câncer de colo uterino: motivos que influenciam a não realização do exame de papanicolaou. Revista Enfermagem Contemporânea. 4(2):179-188, 2015.

RC: 67822

Disponível em: 
SILVA, M.A; TEIXEIRA, E.M.B; FERRARI, R.A.P; CESTARI, M.E.W; CARDELLI, A.M. Fatores relacionados a não adesão à realização do exame de Papanicolau. Rev Rene. 16(4).532-9. 2015.

Представлено: Ноябрь 2020 года.

Утверждено: Ноябрь 2020 года.

RC: 67822

Disponível em:

https://www.nucleodoconhecimento.com.br/здравоохранение/случаи-рака-шейки 